\title{
La Ínsula Barataria: la forma de su relato
}

\author{
JUAN BAUTISTA AVALlE ARCE \\ Universidad de California, Santa Bárbara
}

Para el año de 1615 el humilde Sancho Panza tuvo su terrenal apoteosis en circunstancias tan graciosas y ridículas como extraordinarias, y que hoy quiero analizar en cierto detalle, muy en particular en su aspecto formal. Dicha apoteosis no fue inesperada, sino que fue sabiamente introducida en el relato de su vida. En el palacio de los Duques el capellán de la casa ataca soezmente a don Quijote, y con menos virulencia a Sancho. Uno de los resultados de este enfrentamiento verbal es que el Duque promete a Sancho: "Os mando el gobierno de una [ínsula] que tengo de nones, de no pequeña calidad" (II, XXXII). La realidad de dicha gobernación se hace esperar, sin embargo, por bastante tiempo, ya que Sancho no viajará a ella hasta el capítulo XLV. Pero el autor tiene buen cuidado de que el tema se mantenga en la memoria del lector por un rico sistema de alusiones, entre las que destaca la graciosísima carta de Sancho a su mujer, en el capítulo XXXVI, en la que le da noticia de tan despampanante acontecimiento. Con fines ulteriores quiero dejar constancia de que dicha carta es la primera que se inserta en el Quijote de 1615. Tiempo habrá de hablar de las otras seis que allí se contienen.

Por fin llega el momento de la partida de Sancho para su añorada ínsula. Entre los preparativos ocurre una cosa extraordinaria: por primera vez en toda la novela el autor se encara sin ambages con su materia artística para discurrir claramente acerca de las dificultades y problemas de su composición. Su actitud y palabras son muy seme- 
jantes a las de Ercilla en 1589, en el prólogo a la segunda parte de su Araucana. Ahora es Cide Hamete Benengeli quien, al comienzo del capitulo XLIV, se queja y declara que «en esta segunda parte no quiso ingerir novelas sueltas ni pegadizas, sino algunos episodios que lo pareciesen, nacidos en los mesmos sucesos que la verdad ofrece». No cabe duda. Lo que seguirá, el gobierno de Sancho en la ínsula Barataria, será un episodio (o digresión, nombre alterno en la estética de la época), nacido del propio vivir de los personajes. La ampliación del argumento, que da la buscada variedad al relato, se efectúa desde dentro de las vidas de los protagonistas, no con la artificialidad de los cuentos intercalados en 1605, ya se tratase de los enamorados de la Sierra Morena, o de la lectura del cuento del Curioso Impertinente. La amplificatio (el término consagrado por la retórica tradicional) se concibe ahora en su sentido horizontal (siguiendo la vida de Sancho, en este caso), y no vertical, como había ocurrido en 1605, cuando los cuentos interpolados cortaban el argumento de arriba abajo.

Al llegar a este punto debo advertir que en Italia, tierra repleta de polémicas literarias para esta misma época, había estallado una de las más ruidosas acerca de esta búsqueda de variedad y riqueza en la obra literaria. Los nombres que actuaron como estandartes en esta aparatosa batalla fueron los de Ariosto y Tasso. Los defensores de éste propugnaban la unidad del argumento, mientras que los partidarios de Ariosto abogaban por su riqueza y multiplicidad, Lionardo Salviati, acérrimo defensor de Ariosto, declaraba en 1584 que la belleza del Orlando Furioso radicaba en que consistía en una "tela larga, e magnifica, e ripiena di molte fila». Esto es el Quijote de 1605. La medida en que se superan, ahora en 1615, estos criterios estéticos es algo de lo que quiero ocuparme.

Y mi cuento me retrotrae a la apoteósica gobernación de Sancho. La partida para esa «ínsula hecha y derecha, redonda y bien proporcionada", como la describe el socarrón del Duque (cap. XLII), está precedida por unos extraordinarios consejos de don Quijote a su escudero, en los que trata de mejorarle en su condición de "porro sin madrugar ni trasnochar», como le llama a su cara. La versión escrita de estos "castigos y documentos" llega a manos de los Duques, "quienes llevando adelante sus burlas, aquella tarde enviaron a Sancho con mucho acompañamiento al lugar que para él había de ser ínsulap (cap. XLIV). Y en ese momento se da una extraordinaria ocurrencia: amo y escudero se separan, don Quijote queda en el palacio de los Duques mientras Sancho emprende camino a su gobernación. El amo 
queda en soledad acompañada, bien es cierto, pero tan insólito hecho -que don Quijote quede solo sin Sancho-, nos debe prevenir de que algo extraordinario está por ocurrir. Algo semejante únicamente había sucedido en dos ocasiones anteriores (la penitencia en Sierra Morena de 1605, y la cueva de Montesinos en 1615), ambas preñadísimas del más profundo significado.

Algo de lo incomparable que nos espera en el transcurso del capítulo XLIV al XLV es que el relato se escinde, el argumento se divide en dos hilos, uno que seguirá a Sancho en la Ínsula Barataria y el otro que acompañará a don Quijote en sus desvelados paseos por el palacio de los Duques. El viejo concepto aristotélico de unidad artística se pone a dura prueba en este mismo momento. Un crítico italiano contemporáneo de Cervantes nos dio excelente definición de dicho concepto aristotélico de unidad. Me refiero a Giovambattista Strozzi y su tratado Dell'unità della favola (1599), donde dice que ésta debe ser «Indivisibile in sé, e divisa dell'altre» (indivisible en sí, pero dividida de las otras cosas). Aquí Cervantes no ha hecho ni más ni menos que dividir lo indivisible, y al así hacerlo ha violentado un principio fundamental del neoaristotelismo imperante. Volvamos por un momento los ojos de la memoria e imaginación a la controversia Ariosto versus Tasso, que mencioné hace poco. Los entusiastas de Ariosto ven la unidad argumental (defendida a machamartillo por los partidarios del Tasso) como un desmedro de la obra de arte, porque así se elimina el episodio, el ornamento y la sustancia, como recordará el mismo Lionardo Salviati en su discurso Degli Accademici della Crusca difesa dell'Orlando Furioso dell'Ariosto, de 1584, ya citado.

Lo que estos estetas renacentistas están haciendo es romper una lanza en defensa del viejo principio estructural del Medioevo literario de la amplificatio. Desde la época en que Sócrates ironizó las prácticas forenses de Tisias y Gorgias en el Fedro de Platón, la amplificatio se convirtió en la piedra angular de la oratoria y de la retórica. En el arte narrativo, que es el que me concierne, ya había dictaminado Quintiliano en su Institutio Oratoria (del siglo I de Cristo) que un elemento potestativo de la narratio era la digressio, término abundante en sinónimos. Y es la digressio la que ponía al narrador en el camino real de la amplificatio. El uso de las digresiones será, precisamente, lo que identificará la narratio partilis o expositio partita, forma muy preciada del arte de narrar desde la época de Marciano Capella y su De nuptiis Mercurii et Philologiae, del siglo V y de enorme estela en el arte medieval. Como botón de muestra del Medioevo: Geoffroi de 
Vinsauf y su Poetria nova, de hacia 1210, donde insiste en la importancia capital de la digressio, pero siempre si ésta nos retrotrae al punto de partida, «Deinde revertor / unde prius digressus sum».

Todo esto es algo, muy poco, del trasfondo teórico contra el que se desempeña el arte narrativo del novelista Cervantes. No creo necesario advertir de que mis excesos de pedantesca erudición no implican, en absoluto, que Cervantes haya tenido las mismas autoridades a los puntos de la pluma. Con seguridad, muchos de los nombres que he mencionado le producirían, a lo más, sorprendida extrañeza. La verdadera efectividad actuante la debemos atribuir a los ejemplos literarios (que no de teoría literaria) que sabemos por repetida admisión propia que él conoció, leyó y meditó. Hoy quiero destacar y considerar dos. Los dos ejemplos que he escogido están en la propia entraña artística del Quijote, y sus protagonistas comparten sus sustancias medulares en el nacimiento de don Quijote. Me refiero al Amadís de Gaula, viejísimo roman castellano. Advierto que uso el galicismo roman con toda intención y abogo por su uso, tanto más preciso e ilustrativo que novela de caballerías, o bien libro de caballerias. El Amadís, puesto al alcance de todos los lectores peninsulares por la muy sabia refundición de Garci Rodríguez de Montalvo de 1508. Mi otro ejemplo es el Orlando Furioso de Ariosto, de 1516. Demasiadas son las alusiones a estos dos libros en el curso del Quijote como para dudar de su importancia capital en su ideación. trata de una verdad inconcusa, algo que no hay que demostrar. Y es allí, en estos dos libros (para no pecar de más insulsa erudición), donde Cervantes encontró los modelos, efectivos y actuantes, que habían puesto a la práctica los viejos preceptos retóricos que he enumerado.

Pero antes de entrar en materia será bueno un inciso aclaratorio. Para nosotros la amplificatio es algo así como una reliquia de la prehistoria literaria, y al usarla Cervantes se puede entender que éste practicaba una forma de arqueología literaria, que se refugiaba a sabiendas en arcaicas formas narrativas. Muy al contrario. En la práctica de la amplificatio Cervantes estaba con los mejores de su época. No podía ser de otra manera. Otro inmarcesible ingenio español de ese momento, Lope de Vega, decía esto sobre el uso de la amplificatio en una epístola de crítica literaria que dedicó al poeta sevillano don Juan de Arguijo y que recogió al final de sus Rimas de 1609: «La amplificación es la más gallarda figura de la Retórica, y que más majestad causa a la oración suelta». Para 1670 el francés Molière, en Le bourgeois gentilhomme, hace que el Maestro de Filosofía dé 
una lección práctica de Retórica al inefable Monsieur Jourdain (el que hablaba en prosa sin saberlo) y lo primero que le aconseja es el uso de la amplificatio: "Il faut bien étendre [amplificar] un peu la chose», son sus palabras. El aprecio de la amplificatio como alta gala del escribir une ingenios tan dispares como Cervantes, Lope de Vega y Molière. Con esto bien claro, puedo seguir adelante.

En la literatura medieval la amplificatio dará características únicas a la forma del relato que estructura la caballeresca arturiana, muy en particular en su más destacado y acabado ejemplo, el ciclo de la Vulgata, con el Lancelot propre a la cabeza. Fue el uso heteróclito y constante de la amplificatio en el Lancelot, precisamente, lo que permitió al medievalista francés Ferdinand Lot identificar y estudiar por primera vez, en 1918, la técnica narrativa indisociable del roman arturiano, y que él denominó entrelacement, que hoy en día los críticos ingleses llaman interlace, y que nosotros bien podemos denominar entrelazado. Lo que designa el entrelazado es esa enloquecedora forma del relato en que el argumento salta continuamente de las acciones de un personaje a las de un segundo, para páginas después saltar a las de un tercero, y así entrelazar las aventuras de un caballero con las de otro y otro, y otro, como los hilos de un tapiz o los inacabables arabescos de las mayúsculas iluminadas de los manuscritos medievales. Así describe la técnica del entrelazado su mejor estudioso actual, el medievalista anglo-francés Eugène Vinaver.

Al llegar a este punto lo mejor será ejemplificar el uso de la amplificatio y la digressio en algún relato medieval, como para no perdernos todos en vagas abstracciones y teorías. Y no encuentro mejor texto para ilustrarnos (y más apropiado, dadas las circunstancias) que el Amadís de Gaula, ya que el Amadís no sólo es descendiente directo de la caballeresca arturiana, sino que es también, en su versión primitiva, la españolización más original y efectiva del mito de Tristán e Iseo, aparte de ser el declarado modelo de don Quijote de la Mancha. En el Amadís la técnica del entrelazado es connatural del libro I, muy poco afectado por el bisturi refundidor de Montalvo; aunque con frecuencia decreciente, también se puede hallar en los otros tres libros. Veamos un ejemplo bien claro. En el capítulo XXIV están juntos Amadís, su hermano Galaor y su amigo Balays de Carsante, que van camino de la corte del rey Lisuarte. Pero en una encrucijada hallan un caballero armado y muerto, tendido en un rico lecho, con cirios ardientes, pero no hay nadie alrededor. Nuestros tres caballeros deciden quedarse hasta averiguar la verdad del caso. Llega otro caballe- 
ro con dos escuderos y una doncella, a quien castiga rudamente con su lanza. Amadís de inmediato corre a remediar tan cruda injusticia. Con el cuerpo muerto quedan Galaor y Balays, hasta que llega otro caballero herido, quien se porta con arrogancia y Balays cabalga para aleccionarle. Queda Galaor solo con el muerto, se queda dormido y al despertar el cuerpo muerto ha desaparecido. Galaor sale a buscarlo, guiado por una doncella. Y termina el capítulo XXIV. El capítulo XXV sigue las aventuras de Galaor. El capítulo XXVI representa un brusco corte narrativo en el tapiz del relato porque se siguen las aventuras de Amadís, que se continúan en el capítulo XXVII. El capítulo XXVIII representa nuevo corte narrativo porque pasamos a seguir las aventuras de Balays. A finales del capítulo Balays vuelve a la encrucijada, donde encuentra a Amadís y Galaor. Juntos los tres reemprenden el camino de la corte del rey Lisuarte.

El argumento del roman ha sido ampliado al narrar las aventuras paralelas de los tres caballeros, que, a su vez, constituyen digresiones respecto al relato medular. La amplificatio aparece fuertemente montada sobre la digressio, la última de las cuales retrotrae el argumento a su punto de partida. Todo tal cual lo dictaminaba Geoffroi de Vinsauf: "Deinde revertor / unde prius digressus sum». La amplificatio comienza con nuestros tres caballeros camino de la corte del rey Lisuarte, y su última digressio los deja en ese mismo camino.

Ahora paso a Ariosto, el otro punto de comparación en mi análisis de hoy. Dado su concepto rector del poeta como demiurgo de su poema, Ariosto pone a usos inéditos la técnica de la amplificatio, digressio y entrelazado, al servicio de uno de los más brillantes estilos poético-narrativos del Renacimiento. Pero muy consciente de su papel de deus occasionatus del mundo poético de su Orlando Furioso, él personaliza en su yo el papel del autor. Los cortes en su tapiz narrativo (lo que él llamó «la gran tela ch’io lavoro», canto XIII) se dan, en consecuencia, con inconfundible superioridad irónica, y esto, a su vez, da características únicas a su técnica del entrelazado, que él había heredado del roman medieval. Baste, de momento, un ejemplo de su dominio imperial de materia y forma: "D'una cosa in un' altra in modo entrai, / Che mal di Bradamante mi sovenne. / Soviemmene ora; e vo' narrarne inanti / Che di Rinaldo e di Gradasso io canti. / Ma bisogna anco, prima ch'io ne parli, / Che d'Agramante io vi ragioni un poco" (canto XXXII: "He pasado de tal forma de una cosa en otra que mal me he acordado de Bradamante: ahora me he acordado de ella y quiero contaros de ella antes de cantar de Rinaldo y de Gra- 
dasso. Pero es todavía necesario, antes de hablar de ella que os cuente algo de Agramante»). Tres hilos argumentales en su entrelazado (los que él llamó "molte fila») maneja en este momento el Poeta (el de Bradamante, el de Rinaldo y el de Agramante), y con afectada e irónica desgana pretende jugar con ellos sin decidirse a escoger uno. La vieja técnica del entrelazado jamás se había visto en tal brete. O bien consideremos este otro ejemplo, en que el yo del Poeta se responsabiliza personalmente por el inminente entrelazado narrativo, al mismo tiempo que sus quejas ante la monotonía de su materia nos deben recordar las posteriores declaraciones de Ercilla y los lamentos de Cide Hamete Benengeli que ya he mencionado. Este es el ejemplo: “Ma perché non convien che sempre io dica, / Ne ch'io vi occupi sempre in una cosa; / Io lascieró Ruggiero in questo caldo, / e giró in Scozia a ritrovar Rinaldo" (canto VIII: "No conviene que hable yo siempre de la misma cosa o que os mantenga ocupados con una sola cosa, dejaré a Ruggiero en este caldo e iré a Escocia a buscar a Rinaldo").

He recogido suficientes antecedentes literarios, teóricos y prácticos como para poder acercarnos con cierta confianza al análisis del episodio de la Insula Barataria. Conviene recordar aquí que Giraldi Cinthio llamaba digressioni a los episodios en su Discorso intorno al comporre de i Romanzi, de 1554, como para no olvidar que, en sustancia y en forma implícita, nos hallamos ante un nuevo caso de amplificatio, digressio y entrelazado. Ya hemos visto que el propio Cide $\mathrm{Ha}$ mete Benengeli llama episodio a este entrelazado de diez capítulos (del XLV al LIV), en que los hilos vitales y argumentales corren por dos caminos distintos (don Quijote y Sancho Panza), que bien pronto se ampliarán a tres, con el agregado de Teresa Panza. Un breve resumen nos pondrá ante los ojos de la imaginación la naturaleza del episodio, como para poder apreciar mejor la forma en que Cervantes supera las viejas técnicas narrativas del roman, y con este término ahora me refiero de consuno al Amadís y al Orlando Furioso.

Hemos visto que todo se pone en marcha con un toque de atención al discreto lector: algo inusitado y de máximo interés está por ocurrir, pero lo que sigue es una trasnochada aventura amorosa de don Quijote, la de la enamorada Altisidora. Sólo las últimas líneas del capítulo XLIV confirman nuestras expectativas de algo nuevo. El despechado don Quijote ha vuelto a su lecho, «donde le dejaremos por ahora, porque nos está llamando el gran Sancho Panza, que quiere dar principio a su famoso gobierno". El corte en el tapiz narrativo nos aboca, ahora como antes en el roman, a la técnica del entrelazado, 
aquí con evidente eco de Ariosto: «Lasciamo andar Astolfo, che fará buon camino, / e torniamo a Rinaldo paladino" (canto IV), o alguna de las múltiples fórmulas análogas del Orlando Furioso. Pero en el Orlando la primera persona verbal, ya sea del singular o del plural, siempre se debe identificar con el Poeta. El Quijote ha creado una problemática imponderable, porque no podemos saber si aquí habla Cide Hamete, o su traductor, o algún otro intermediario antes de llegar a Cervantes. Pasamos al capítulo XLV y la cosa se ahonda, porque el segundo párrafo comienza con un yo inasible: «Digo, pues...». Pero no debe ser éste el problema a exponer hoy.

El capítulo XLV se hace cargo de varios graciosos juicios de Sancho, para terminar: "Y quédese aquí el buen Sancho, que es mucha la priesa que nos da su amo, alborozado con la música de Altisidora». El capítulo XLVI narra el espanto cencerril y gatuno que afectó a don Quijote, para terminar con otra fórmula, que, de manera parecida, anuncia hilo distinto del entrelazado: "Donde le sucedió otra aventura más gustosa que la pasada, la cual no quiere su historiador contar ahora, por acudir a Sancho Panza, que andaba muy solícito y muy gracicso en su gobierno». Obsérvese, de pasada, que la cronología del relato se supedita, en forma explícita, al riguroso entrelazado en que nos ha embarcado el autor.

El capítulo XLVII contiene el duelo gastronómico entre el gober nador Sancho Panza y el doctor Pedro Recio de Tirteafuera, y nos depara una carta del Duque, en que le previene de un asalto enemigo. $Y$ aquí debo abrir un pequeño excurso: el Quijote de 1615 sólo contiene una carta con anterioridad a ésta, en el capítulo XXXVI, de Sancho a su mujer, en la que le anuncia su nombramiento como gobernador de la Insula Barataria. El episodio de Barataria contiene otras seis, asimismo cartas de tipo noticiero. Y éstas son todas para 1615. En 1605 el texto contiene ocho cartas, todas relacionadas con los amantes de Sierra Morena o con la historia del Capitán Cautivo, y todas son cartas de amores. Las consecuencias a entresacar de este breve recuento vendrán más tarde, ahora sólo deseo alertar al público acerca de este fenómeno. El capítulo XLVII termina con el protocolario corte en el tapiz narrativo que impone la técnica del entrelazado: "pero dejemos con su cólera a Sancho, y ándese la paz en el corro, y volvamos a don Quijote».

El capítulo XLVIII nos brinda la inolvidable entrevista nocturna entre don Quijote y doña Rodríguez, para terminar, con retintín 
ariostesco: «Sancho Panza nos llama, y el buen concierto de la historia lo pide». El capítulo XLIX relata las peripecias de la ronda nocturna del gobernador, para terminar con estos sugerentes términos: "Con esto se acabó la ronda de aquella noche, y de allí a dos días el gobierno, con que se destroncaron y borraron todos sus designios, como se verá adelante». Evidentemente el próximo capítulo no tratará de don Quijote, o sea que se abandona la alternancia como método del entrelazado, pero no se abandona éste, sino que se introduce un nuevo hilo argumental. En efecto, el capítulo L introduce la embajada del paje de la Duquesa a Teresa Panza y Sanchica, o sea una interpolación horizontal, o bien un "episodio nacido de los mesmos sucesos", en palabras de Cide Hamete Benengeli. Incluye, además, una carta noticiera de la Duquesa a Teresa, con envio de unos corales. El capítulo se cierra con promesa de dos nuevas cartas y con una clásica variante en el enunciado del corte en el tapiz narrativo: «Como se verá adelante».

El capítulo LI, otra vez en la ínsula, ofrece la novedad de dos cartas noticieras, una de don Quijote a Sancho, y la otra su respuesta. Al final del capítulo no se anuncia el corte en el tapiz narrativo, pero se efectúa, de todas maneras, ya que el LII presenta la continuación de la aventura palaciega con doña Rodríguez, y dos cartas noticieras de Teresa Panza, una a la Duquesa y la otra a su marido. El final de este capítulo sí vuelve al hieratismo formal del anunciado corte: «Recibiólo la Duquesa con grandísimo gusto, con el cual la dejaremos, por contar el fin que tuvo el gobierno del gran Sancho Panza». De esto se hace cargo el capítulo LIII, que termina sin anuncios de cortes de ningún tipo, lo que no aminora la brusquedad del cambio argumental, ya que el capitulo LIV salta al palacio de los Duques, pero brevemente, para continuar, con fórmula semiarostesca: "Dejémoslos pasar nosotros, como dejamos pasar otras cosas, y vamos a acompañar a Sancho". Este encuentra a su paisano el morisco Ricote, y sigue hacia el palacio de los Duques, para caer en una sima, donde lo encuentra don Quijote. Después de tan larga separación, es el capítulo LV el que se hace cargo de la reunión de amo y escudero. Con ambos juntos otra vez, la digressio de la Insula Barataria ha terminado como quería Geoffroi de Vinsauf, "unde prius digressus sum». Todo parece terminar con triunfante nota de medievalismo formal y retórico. Pero, "bajo el sayal, hay ál».

Efectivamente, el sayal cervantino encubre inéditos triunfos artísticos. Por lo pronto consideremos sus relaciones con el roman, en 
primer lugar según lo ilustró Ariosto. La imitación del Orlando Furioso ha estado muy en el proscenio de la imaginación de Cervantes desde 1605, como lo declaró sin ambages don Quijote al internarse en la Sierra Morena. A la búsqueda allí de la perfección caballeresca decidió unir la penitencia de Amadís en la Peña Pobre con las locuras de Orlando, "cuando halló en una fuente las señales de que Angélica la Bella había cometido vileza con Medoro", como explica nuestro caballero (I, XXV). Pero para 1615 don Quijote ha domeñado sus más despepitantes excesos de locura, y ya no sueña con imitaciones activas del paladín italiano. Dicho tipo de imitaciones correrá ahora por cuenta de Cervantes. Su nuevo e imperial dominio de la técnica del relato le lleva a intentar superar el concepto y uso del episodio, tal cual lo había venido practicando el roman. En 1605 las intervenciones episódicas habían sido verticales, que caían desde fuera sobre las vidas de los personajes centrales, con los cuales no guardaban relación. Tal es el caso de los amantes de Sierra Morena, el Curioso Impertinente y el Capitán Cautivo. Diez años más tarde, en 1615, el novelista ha madurado un nuevo concepto de episodio (digressio), y con éste sus íntimos parientes amplificatio y entrelazado. Ahora, como dijo Cide Hamete Benengeli: «En esta segunda parte no quiso ingerir novelas sueltas ni pegadizas, sino algunos episodios que lo pareciesen, nacidos de los mesmos sucesos" (II, XLIV). Se condenan ahora explícitamente el Curioso Impertinente y el Capitán Cautivo, y se pica la curiosidad del lector con el anuncio de un episodio de los de nuevo cuño, o sea una intervención horizontal, emanada del vivir de los mismos personajes. $\mathrm{Y}$ así se pone en camino, con marchosa galanura, el episodio de la Insula Barataria.

La superioridad sobre la práctica ariostesca debe resultar evidente. Por lo pronto, no hay que recurrir a un nuevo elenco de personajes, ya que el episodio cervantino nace de "los mesmos sucesos». Tampoco hay que acudir a nuevas frondosidades geográficas, como la Escocia a la que tiene que correr el Poeta a la búsqueda de Rinaldo, como cité poco antes, ya que Barataria está tan cerca del palacio de los Duques que el propio Sancho encarece lo corto del camino al abandonar su gobierno (II, LIII). Y tampoco hay que echar mano de estrepitosas dilataciones temporales, porque Sancho gobierna su ínsula menos de una semana. La verosimilitud del episodio, en consecuencia, tiene que repercutir sobre las características del entrelazado, o sea, la forma del relato de tan realista digresión. El entrelazado se practica a base de la alternancia (don Quijote en un capítulo, San- 
cho en el próximo), desde el capítulo XLV al XLIX, donde el autor considera apropiado introducir un nuevo hilo narrativo (también nacido "de los mesmos sucesos»), y así seguimos al paje ducal a la aldea de Teresa Panza. La alternancia no ha tenido tiempo de empalagar, cuando ya está lista, al quite, una nueva forma de amplificatio. $Y$ así, del capítulo LI hasta el final de nuestro episodio el autor se considera justificado, y retoma la técnica de un entrelazado alternante. Como primera recapitulación de lo hasta aquí expuesto, tengo que concurrir con las palabras que Orlando Furioso dirigió a don Quijote en un soneto de 1605: «No puedo ser tu igual».

Ahora paso a analizar la abundancia de cartas que caracteriza nuestro episodio isleño, y que ya he mencionado. Esto nos aparta de Ariosto en la misma medida en que nos aproxima al Amadís de Gaula, porque las epístolas son ajenas al Orlando Furioso, epopeya en verso, al fin, mientras que tienen creciente muestra en el Amadís a partir de la desdeñosa carta de Oriana al caballero y que provocó su penitencia en la Peña Pobre en el libro II. Ahora bien, Garci Rodríguez de Montalvo trabaja dentro de la tradición de la epístola ovidiana y el naciente género, en su época, de la novela sentimental. Pero en el Quijote el uso de cartas tiene distinto sentido en 1605 que en 1615. Ya he dicho que las ocho epístolas de 1605 pertenecen todas a los episodios verticales (o sea que son ajenas a "los mesmos sucesos»), como los amantes de Sierra Morena o el Capitán Cautivo, y que son todas de amores, o sea que son de corte típico de la novelística sentimental. No olvidemos, por lo demás, que fueron precisamente estos tipos de episodios los condenados en 1615. Por contrapartida, todas las cartas de este último año son totalmente ajenas al género sentimental, al punto que se las puede definir, y con razón, como cartas noticieras. Por consiguiente, creo que se puede generalizar y decir que las epístolas de 1615 constituyen un experimento narrativo en la inserción de cartas diarias en el relato literario, de cartas llenas de noticias tan ordinarias como la abundancia de bellotas en la Mancha, por ejemplo. Las cartas de 1605, frente a esto, tienen como único punto de orientación la epístola amorosa tal cual la practicaba la novela sentimental, con lo que todas resultan ser incursiones en la literatura como la última verdad. Para 1615, sin embargo, todas las cartas abren sus páginas a la realidad diaria: bellotas gordas, los enemigos del Duque, o el marido de la Berrueca. En maravilloso y ejemplar contraste esto ocurre, justamente, en un episodio que utiliza y realza, como vehículo expresivo único, la más exquisita técnica del relato li- 
terario conocida hasta entonces, la del entrelazado. El autor ha conjurado, en esta ocasión, una simbiosis en la que cohabitan las técnicas del roman, las epístolas otrora sentimentales y la materialidad de la Mancha. En este nuevo ambiente quedan superadas las formas características del roman. $\mathrm{Y}$ esto me lleva a mi última recapitulación de hoy: la mejor enseñanza del análisis del episodio de la Insula Barataria es cómo se debe usar de la tradición para mejorarla, y esto creo yo que constituye una inmejorable lección para la literatura y para la vida. 